\title{
Effects of Different Shading Rates on the Photosynthesis and Corm Weight of Konjac Plant
}

\author{
Yaoguo QIN ${ }^{1}$, Zesheng YAN ${ }^{1}$, Honghui $\mathrm{GU}^{1}$, Zhengxiang WANG ${ }^{1}$, \\ Xiong JIANG ${ }^{1}$, Zhizhou $\mathrm{CHEN}^{1}$, Fuqing $\mathrm{YANG}^{1}$, Cuiqin $\mathrm{YANG}^{2 *}$
ISichuan Agricultural University, College of Horticulture, Chengdu 611130,China; qinyaoguo@sina.com; 863748012@qq.com; 407959707@qq.com;1095594263@qq.com;2791998606@qq.com;1628579669@qq.com;913188595@qq.com
${ }^{2}$ Sichuan Agricultural University, College of Agriculture, Chengdu 611130, China; ycuiqin@126.com ("corresponding author)

\begin{abstract}
To study the effects of shading level on the photosynthesis and corm weight of konjac plant, the chlorophyll fluorescence parameters, daily variation of relative electron transport rate $(\mathrm{rETR})$, net photosynthetic rate $(\mathrm{Pn})$, and corm weight of konjac plants under different treatments were measured and comparatively analyzed through covered cultivation of biennial seed corms with shade nets at different shading rates $(0 \%, 50 \%, 70 \%$, and $90 \%)$. The results showed that with the increase in shading rate, the maximum photochemical efficiency, potential activity, and non-photochemical quenching of photosystem II (PS II ) of konjac leaves constantly increased, whereas the actual photosynthetic efficiency $\left(\Phi_{\text {PSII }}\right), r E T R$, and photochemical quenching of PS II initially increased and then decreased. This result indicated that moderate shading could enhance the photosynthetic efficiency of konjac leaves. The daily variation of rETR in konjac plants under unshaded treatment showed a bimodal curve, whereas that under shaded treatment displayed a unimodal curve. The rETR of plants with $50 \%$ treatment and $70 \%$ treatment was gradually higher than that under unshaded treatment around noon. The moderate shading could increase the $P \mathrm{n}$ of konjac leaves. The stomatal conductance and transpiration rate of the leaves under shaded treatment were significantly higher than those of the leaves under unshaded treatment. Shading could promote the growth of plants and increase corm weight. The comprehensive comparison shows that the konjac plants had strong photosynthetic capacity and high yield when the shading rate was $50 \%-70 \%$ for the area.
\end{abstract}

Keywords: chlorophyll fluorescence parameter; konjac; photosynthesis; shading

\section{Introduction}

Konjac is the general name of perennial herbs of the Genus Amorphophallus Blume, Family Araceae. One of its representatives, Amorphophallus konjac, is widely distributed in the south of Qinling Mountains, China, to the Himalaya Range in the west, Japan in the east, and Indochina Peninsula in the south (Liu, 2004). Konjac contains a large amount of glucomannan, which has unique physiological functions and physical and chemical properties. It is widely used in food processing, medical and health care, environmental protection, chemical industry, and other fields (Zhang et al., 2005; Chua et al., 2010). In recent years, the demand for konjac and its products has increased in the international market and often exceeds the supply. The planting industry has become a bottleneck in the development of the konjac industry. Thus, how to increase the yield of konjac by a large margin is an urgent problem to be solved.
Konjac is a shade-loving species that prefers scattered and weak light (Inaba and Chonan, 1984; Santosa et al., 2006). Related studies have shown that a certain degree of shading can increase leaf area (Miura and Osada, 1981; Inaba, 1984; Seo et al., 1988; Santosa et al., 2006 ), enhance photosynthetic rate (Miura and Osada, 1981; Liu and Chen, 1984), reduce incidence of disease (Liu and Chen, 1984; Xu et al., 2011), and increase dry matter accumulation (Inaba, 1984) and yield (Douglas et al., 2005; Santosa et al., 2006; Harjoko et al., 2016). Photosynthesis is a key metabolic process in plants, and its efficiency influences plant growth, yield and resistance. Therefore, it can be used as an index to judge the growth and development of plants (Inoue et al., 2004; Evans, 2013). An increasing number of studies have shown that chlorophyll fluorescence signals emitted from plants contain rich photosynthesis information. Chlorophyll fluorescence parameters obtained are considered rapid and nondestructive indicators for measuring the photosynthetic 
function of leaves (Baker, 2008). They have been widely used to study the effects of photosynthetic physiology and environmental stress on leaves and are important indicators of the photosynthetic capacity of plants (Schreiber et al., 1995; Murchie and Lawson, 2013). The effects of environmental factors on photosynthesis can be reflected by chlorophyll fluorescence parameters. However, few reports focused on the effects of shading treatment on the chlorophyll fluorescence parameters of konjac leaves.

In this experiment, the chlorophyll fluorescence parameters, net photosynthetic rate, and corm weight of konjac plants under different shading rates were measured through covered cultivation with different shading rates by using artificial shading, and daily variation of relative electron transport rate (rETR) was explored. Finally, the shading rate suitable for the local growth of konjac was determined through comparison. This study provides a theoretical basis for discussing different cultivation modes of konjac and its application in production.

\section{Materials and Methods}

\section{Materials}

Biennial seed corms of Amorphophallus konjac cv. 'No.1 Chumohua' were obtained from Chuxiong Agricultural Science Research and Extension Institute of Yunnan Province.

The shading nets of $50 \%, 70 \%$ and $90 \%$ shading rate were purchased from the garden trading center in Wenjiang District of Sichuan Province.

\section{Experimental site}

The experiment was conducted from April to October 2016 on the Chengdu Plain $\left(30^{\circ} 70^{\prime} \mathrm{N}, 103^{\circ} 85^{\prime} \mathrm{E}\right.$, and altitude $633 \mathrm{~m}$ ) in Sichuan Province. The experimental area has a humid mid-subtropical monsoon climate with a long duration of high temperature and strong sunshine in summer.

\section{Disinfection of seed corms}

Disease-free and non-invasive konjac seed corms of the same size and about $50 \mathrm{~g}$ in weight were selected. After drying for 2 days in the air, the seed corms were soaked in $72 \%$ agricultural streptomycin (1 g/liter) for $3 \mathrm{~h}$. After drying, the seed corms were soaked again in the same agent for $3 \mathrm{~h}$. Then, the seed corms were taken out for drying.

\section{Sowing}

The seed corms were sowed in April. Before sowing, the substrate was prepared. Peat was mixed with perlite in 2:1 (v/v). $\mathrm{N}(0.15 \mathrm{~g}), \mathrm{P}_{2} \mathrm{O}_{5}(0.1 \mathrm{~g})$, and $\mathrm{K}_{2} \mathrm{O}(0.15 \mathrm{~g})$ were added to $1 \mathrm{~kg}$ of the substrate. After mixing evenly, it was placed in the pot $(25 \mathrm{~cm}$ height $\times 28 \mathrm{~cm}$ diameter $)$. At the time of sowing, holes about $10 \mathrm{~cm}$ deep were dug and the seed corms were obliquely placed into the holes upwards. Finally, fertilizer-free substrates about $8 \mathrm{~cm}$ thick were covered and watered. Each pot was planted with one seed corm of konjac.

\section{Experimental treatment}

After the leaves were expanded, black shading nets were used to cover the steel pipe frame at a height of $2 \mathrm{~m}$ to shade. The set shading rates were $0 \%, 50 \%, 70 \%$, and $90 \%$, where $0 \%$ referred to full exposure (no shading net) as the control. A total of four treatments were established, with 50 plants for each treatment. Other managements were performed following common practices for the area.

\section{Determination of chlorophyll fluorescence parameters}

In late July, during the bulge period of new corms, the top leaflets of five plants were randomly selected from each treatment. The minimum fluorescence $\left(F_{\mathrm{O}}\right)$ and maximum fluorescence $\left(F_{\mathrm{m}}\right)$ after dark-acclimation for $30 \mathrm{~min}$ were determined by using a portable modulated chlorophyll fluorometer (PAM-2500, Walz, Germany). After the actinic light was switched on, the maximum fluorescence $\left(F \mathrm{~m}\right.$ ') and steady fluorescence $\left(F_{\mathrm{S}}\right)$ under light-acclimation were determined. After the actinic light was turned off, the minimum fluorescence $\left(F_{\mathrm{O}}{ }^{\prime}\right)$ under far-red light was determined. The chlorophyll fluorescence parameters for comparison were calculated as follows: the maximum photochemical efficiency of PS II $F_{\mathrm{V}} / F_{\mathrm{m}}=\left(F_{\mathrm{m}}-F_{\mathrm{O}}\right) / F_{\mathrm{m}}$, potential activity $F_{\mathrm{V}} / F_{\mathrm{O}}=\left(F_{\mathrm{m}}-F_{\mathrm{O}}\right) / F_{\mathrm{O}}$, actual photosynthetic efficiency $\Phi_{\mathrm{PSII}}=\left(F_{\mathrm{m}}{ }^{\prime}-F_{\mathrm{S}}\right) / F_{\mathrm{m}}$ ', relative electron transport rate $\mathrm{rETR}=\left(F_{\mathrm{m}}{ }^{\prime}-F_{\mathrm{S}}\right) / F_{\mathrm{m}}{ }^{\prime} \times \mathrm{PAR} \times 0.84 \times 0.5$, photochemical quenching $\mathrm{qP}=\left(F_{\mathrm{m}}{ }^{\prime}-F_{\mathrm{s}}\right) /\left(F_{\mathrm{m}}{ }^{\prime}-F_{\mathrm{O}}{ }^{\prime}\right)$, non-photochemical quenching $\mathrm{NPQ}=\left(F \mathrm{~m}-F_{\mathrm{m}}{ }^{\prime}\right) / F_{\mathrm{m}}$ ' (Roháček, 2002; Murchie and Lawson, 2013).

\section{Determination of leaf $r$ ETR in diurnal process}

From 6:00 to 18:00 in a clear day, the top leaflets of five plants were randomly selected from each treatment. The Leaf-Clip Holder 2030-B of the PAM-2500 was used to nip the leaflets every $2 \mathrm{~h}$ to determinate the photosynthetically active radiation (PAR). After the saturation pulse was switched on, $\Phi_{\text {PSII }}$ and rETR were determined. With the mean value of rETR measured as the ordinate, its daily variation curve in the diurnal process was made.

\section{Determination of leaf photosynthetic gas exchange parameters}

Starting from 9:00 in a clear day, the top leaflets of five plants were randomly selected from each treatment. The net photosynthetic rate $(P \mathrm{n})$, stomatal conductance $(G \mathrm{~s})$, intercellular $\mathrm{CO}_{2}$ concentration $(\mathrm{Ci})$, and transpiration rate $\left(T_{\mathrm{r}}\right)$ were determined by using a portable photosynthesis system (LI-6400XT, Li-Cor, USA).

\section{Determination of plant growth indexes and corm weight}

During the filling period of corms, 10 plants were randomly selected from each treatment to determine the plant height, leaf width, petiole diameter and leaf area. When corms were harvested, corms of 20 plants were selected from each treatment to measure the weight of corms.

\section{Statistical analysis}

Data were analyzed with one-way ANOVA using SPSS version 19 (SPSS Inc., Chicago, USA) for Windows and means were compared with Duncan's multiple range test at $5 \%$ level of significance. 


\section{Results}

\section{Effects of different shading rates on chlorophyll fluorescence parameters of konjac leaves}

As shown in Table 1, with the increase in shading rate, $F_{\mathrm{v}} / F_{\mathrm{m}}$ and $F_{\mathrm{V}} / F_{\mathrm{O}}$ constantly increased. The data under shaded treatment were significantly higher than those under the control treatment. $\Phi_{\text {PSII }}$ rETR, and $\mathrm{qP}$ initially increased and then decreased. The data under a certain shading rate $(70 \%)$ were significantly higher than those of the control. NPQ gradually increased as the light intensity was weakened. The figure under the shading rate of $90 \%$ was significantly higher than that of the control. This result indicates that a certain degree of shading can improve chlorophyll fluorescence parameters and enhance the photosynthetic efficiency of konjac plant leaves.

\section{Daily variation of rETR of konjac leaves under different} shading rates treatments

As can be seen in Fig. 1, the rETR of the leaves under different treatments initially increased and then decreased with time. However, the rETR of the control gradually increased after decreasing to the lowest at 14:00. The daily variation of rETR in plants under unshaded treatment showed a bimodal curve, whereas that under shaded treatment displayed a unimodal curve. The rETRs of the shaded treatments and the control were different in time points when the peaks occurred. In the control treatment, the peak value occurred at the earliest time. Under the

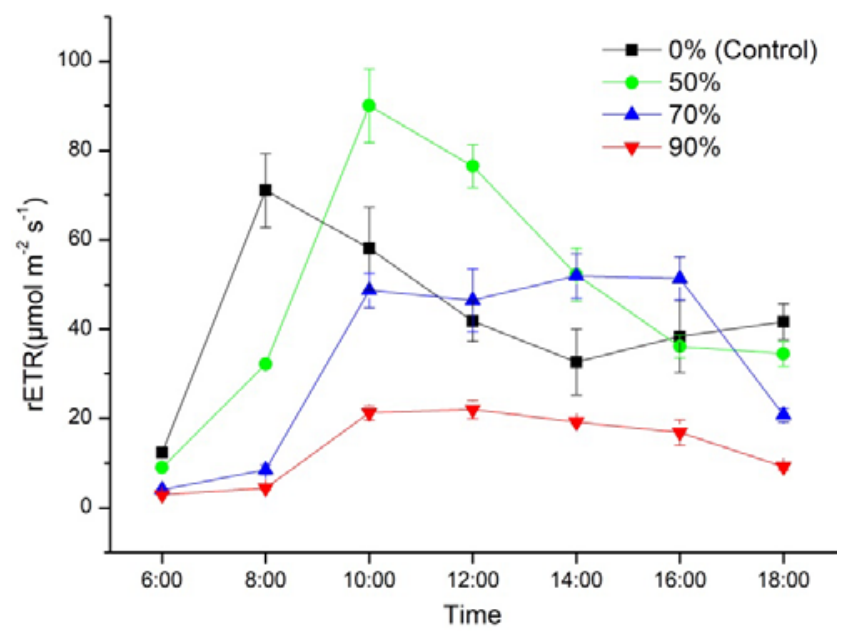

Fig. 1 Daily variation of rETR shaded treatments, the peak values occurred at 10:00 or later. Among the three shading rates, rETR changed more significantly at low shading rates. From 10:00 to $14: 00,50 \%$ treatment induced the highest rETR. From 12:00 to 16:00, rETR under $70 \%$ treatment was higher than that of the control. For plants under $90 \%$ treatment, its rETR was always the lowest because of the low PAR.

\section{Effects of different shading rates on photosynthetic gas} exchange parameters of konjac leaves

As shown in Table 2, different shading rate treatments had significant effects on $P \mathrm{n}, G_{\mathrm{s}}$, and $T r$, but not on $C_{\mathrm{i}}$. With the increase in shading rate, $P_{\mathrm{n}}$ initially increased and then decreased. $P$ n under moderate shading rate was the highest and no significant differences were observed between $50 \%$ and $70 \%$ shading rate. This result indicates that proper shading can improve the $P \mathrm{n}$ of konjac leaves. No significant difference in $G$ s and $T r$ was found among the three shading treatments, and they were all higher than those of the control. The difference in $C \mathrm{i}$ among the different treatments was not significant.

\section{Effects of different shading rates on growth indexes and} corm weight of konjac plant

It can be seen from Table 3 that different shading rate treatments had significant effects on plant height, leaf width and leaf area of the konjac plants, but had no significant effect on petiole diameter. No significant difference in plant height was found between shading treatments, but all were significantly higher than that of the control. No significant difference in leaf width was observed between $70 \%$ and $90 \%$ shading treatments, and it was significantly greater than those under $50 \%$ shading rate and the control treatment. The difference between the latter two parties was not significant. No significant difference in petiole diameter was found among different treatments. The leaf area increased with increasing shading rate. It was greater under $90 \%$ shading rate, which was not significantly different from $70 \%$ shading rate. The leaf area was smaller under the control treatment. This result indicates that the plant growth indexes under the shading treatments were better than those under the unshaded treatment. Different shading treatments had a significant effect on corm weight of konjac. Corm weight under $70 \%$ shading treatment was the largest, followed by $90 \%$ and $50 \%$ shading treatments, and corm weight under the control treatment was the smallest. This result shows that a certain shading can improve the yield of konjac.

Table 1. Effects of different shading rates on chlorophyll fluorescence parameters of konjac leaves

\begin{tabular}{ccccccc}
\hline Shading rate (\%) & $F_{\mathrm{V}} / F_{\mathrm{m}}$ & $F_{\mathrm{V}} / F_{\mathrm{O}}$ & ФPSII & $\begin{array}{c}\mathrm{rETR} \\
\left(\mu \mathrm{mol} \cdot \mathrm{m}^{-2} \cdot \mathrm{s}^{-1}\right)\end{array}$ & $\mathrm{qP}$ & $\mathrm{NPQ}$ \\
\hline $0($ Control $)$ & $0.760 \pm 0.004 \mathrm{c}$ & $3.170 \pm 0.076 \mathrm{c}$ & $0.548 \pm 0.019 \mathrm{~b}$ & $45.403 \pm 1.653 \mathrm{~b}$ & $0.775 \pm 0.016 \mathrm{~b}$ & $0.477 \pm 0.025 \mathrm{~b}$ \\
50 & $0.786 \pm 0.007 \mathrm{~b}$ & $3.683 \pm 0.165 \mathrm{~b}$ & $0.566 \pm 0.001 \mathrm{ab}$ & $47.089 \pm 0.022 \mathrm{ab}$ & $0.799 \pm 0.003 \mathrm{ab}$ & $0.581 \pm 0.054 \mathrm{~b}$ \\
70 & $0.805 \pm 0.004 \mathrm{ab}$ & $4.134 \pm 0.150 \mathrm{ab}$ & $0.606 \pm 0.005 \mathrm{a}$ & $50.644 \pm 0.589 \mathrm{a}$ & $0.825 \pm 0.004 \mathrm{a}$ & $0.644 \pm 0.061 \mathrm{ab}$ \\
90 & $0.814 \pm 0.003 \mathrm{a}$ & $4.387 \pm 0.161 \mathrm{a}$ & $0.584 \pm 0.012 \mathrm{ab}$ & $48.833 \pm 1.033 \mathrm{ab}$ & $0.808 \pm 0.011 \mathrm{ab}$ & $0.803 \pm 0.078 \mathrm{a}$ \\
\hline
\end{tabular}


Table 2. Effects of different shading rates on the photosynthetic gas exchange parameters of konjac leaves

\begin{tabular}{ccccc}
\hline Shading rate (\%) & $\begin{array}{c}P \mathrm{n} \\
\left(\mu \mathrm{mol} \mathrm{CO} \cdot \mathrm{m}^{-2} \cdot \mathrm{s}^{-1}\right)\end{array}$ & $\begin{array}{c}G \mathrm{~s} \\
\left(\mathrm{mmol} \mathrm{H}_{2} \mathrm{O} \cdot \mathrm{m}^{-2} \cdot \mathrm{s}^{-1}\right)\end{array}$ & $\begin{array}{c}\mathrm{Ci} \\
\left(\mu \mathrm{mol} \mathrm{CO} \cdot \mathrm{m}^{-2} \cdot \mathrm{s}^{-1}\right)\end{array}$ & $\begin{array}{c}T r \\
\left(\mathrm{mmol} \mathrm{H}_{2} \mathrm{O} \cdot \mathrm{m}^{-2} \cdot \mathrm{s}^{-1}\right)\end{array}$ \\
\hline 0 (Control) & $8.27 \pm 0.14 \mathrm{bc}$ & $132.60 \pm 2.90 \mathrm{~b}$ & $285.92 \pm 1.02 \mathrm{a}$ & $1.70 \pm 0.05 \mathrm{~b}$ \\
50 & $10.37 \pm 0.22 \mathrm{a}$ & $218.76 \pm 12.15 \mathrm{a}$ & $301.38 \pm 7.38 \mathrm{a}$ & $2.42 \pm 0.09 \mathrm{a}$ \\
70 & $9.49 \pm 0.17 \mathrm{ab}$ & $194.34 \pm 14.97 \mathrm{a}$ & $286.16 \pm 10.62 \mathrm{a}$ & $2.38 \pm 0.08 \mathrm{a}$ \\
90 & $7.56 \pm 0.55 \mathrm{c}$ & $181.96 \pm 12.45 \mathrm{a}$ & $315.87 \pm 10.14 \mathrm{a}$ & $2.12 \pm 0.10 \mathrm{a}$ \\
\hline
\end{tabular}

Table 3. Effects of different shading rates on plant growth indexes and corm weight of konjac

\begin{tabular}{cccccc}
\hline Shading rate $(\%)$ & Plant height $(\mathrm{cm})$ & $\begin{array}{c}\text { Leaf width } \\
(\mathrm{cm})\end{array}$ & Petiole diameter $(\mathrm{mm})$ & $\begin{array}{c}\text { Leaf area } \\
\left(\mathrm{dm}^{2}\right)\end{array}$ & Corm weight $(\mathrm{g})$ \\
\hline $0($ Control $)$ & $27.20 \pm 2.94 \mathrm{~b}$ & $48.38 \pm 2.81 \mathrm{~b}$ & $16.87 \pm 1.21 \mathrm{a}$ & $6.66 \pm 0.72 \mathrm{c}$ & $106.46 \pm 0.94 \mathrm{c}$ \\
50 & $47.44 \pm 3.71 \mathrm{a}$ & $54.67 \pm 1.89 \mathrm{~b}$ & $17.69 \pm 0.48 \mathrm{a}$ & $10.18 \pm 0.93 \mathrm{~b}$ & $141.98 \pm 0.87 \mathrm{~b}$ \\
70 & $43.35 \pm 4.47 \mathrm{a}$ & $69.73 \pm 4.22 \mathrm{a}$ & $15.42 \pm 0.95 \mathrm{a}$ & $12.18 \pm 1.04 \mathrm{ab}$ & $172.24 \pm 0.57 \mathrm{a}$ \\
90 & $45.50 \pm 2.84 \mathrm{a}$ & $64.73 \pm 2.93 \mathrm{a}$ & $15.76 \pm 0.55 \mathrm{a}$ & $15.36 \pm 2.26 \mathrm{a}$ & $153.34 \pm 0.61 \mathrm{~b}$ \\
\hline
\end{tabular}

\section{Discussion}

\section{Effects of different shading rates on chlorophyll fluorescence parameters of konjac leaves}

Chlorophyll fluorescence parameters are a set of variable values used to describe the photosynthesis mechanism and physiological status of plants (Baker, 2008). They are considered to be probes in vivo for studying the relationship between plant photosynthesis and the environment. The commonly used chlorophyll fluorescence parameters include $F_{\mathrm{V}} / F_{\mathrm{m}}, F_{\mathrm{V}} / F_{\mathrm{O}}, \Phi_{\text {PSII }}$, rETR, $\mathrm{qP}$, and NPQ. $F_{\mathrm{V}} / F_{\mathrm{m}}$ is the maximum photochemical quantum yield of PS II, which reflects the maximum photosynthetic efficiency of PS II. $F_{\mathrm{V}} / F_{\mathrm{O}}$ is commonly used to measure the potential activity of PS II (Genty et al., 1989). In this experiment, the $F_{\mathrm{V}} / F_{\mathrm{m}}$ and $F_{\mathrm{V}} / F_{\mathrm{O}}$ of the plants under the control treatment were lower than those of the plants under the shaded treatments. In general, a decline in two parameter values indicates that plants are under stress (Bjorkman and Demming, 1987). Thus, konjac plants are susceptible to environmental stresses, such as strong light and high temperature, which may damage the PS II active center and inhibit the primary reaction process of photosynthesis. Under a certain degree of shading, the two parameters improved to a certain extent, which increased the maximum photosynthetic efficiency. This is consistent with the results obtained by the shading treatment of Subterranean Clover (Mauro et al., 2011) and Leymus chinensis (Yang et al., 2018). $\Phi_{\text {PSII }}$ refers to the actual quantum yield of PS II, reflecting the actual photosynthetic efficiency (Genty et al., 1989). rETR refers to the relative rate of photosynthetic electron transport of PS II, which represents the photosynthetic rate (Bjorkman and Demming, 1987). qP refers to fluorescence quenching caused by photosynthesis, namely the proportion of the energy adsorbed by PS II for photochemical reaction, which reflects photosynthetic activity (van Kooten and Snel, 1990). In this experiment, the $\Phi_{\text {PSII }}$, rETR, and qP of konjac leaves grown under longterm strong light were lower than those under the proper shading treatment. This result shows that the accumulation of excess light caused by strong light stress is not conducive to the transfer of excitation energy from the antenna pigment-protein complex to the PS II reaction center, which limits the normal operation of D1 protein and electron transfer efficiency in the PS II reaction center, resulting in photoinhibition. The shading treatments improved the photosynthetic electron transformation ability and transfer rate of plants and effectively enhanced their photosynthetic efficiency and photosynthetic capacity. Similar results were obtained in Amorphophallus albus (Fu et al., 2016). NPQ is used to measure the proportion of energy adsorbed by PS II for thermal dissipation, reflecting the ability of light protection (Koblizek et al., 2001). The shading increased the NPQ in konjac, indicating that the ability of the plant to dissipate excess light energy as heat was enhanced. Konjac is believed to be adaptive to weak light, thus forming a protection mechanism, which agrees with the result that NPQ of Tetrastigma hemsleyanum Diels et Gilg increased with increased shading (Dai et al., 2009).

The rETR of the plants under the control treatment showed a trough at noon under strong light and high temperature, showing a phenomenon of midday depression of photosynthesis. This result is consistent with the experimental results of $\mathrm{Li}$ et al. (2001) that the daily variation in the $P \mathrm{n}$ of konjac showed a bimodal curve. The reason may be that the PS II reaction center is damaged or partially inactivated, and photochemical efficiency is reduced, which leads to photoinhibition. In general, photoinhibition mainly occurs in PS II. Excess light energy leads to toxic substances, including reactive oxygen species, which further damage the photosynthetic apparatus. Covering with shading net weakens the light intensity and thus reduces the photoinhibition degree. This feature becomes more significant as the shading rate is increased.

Effects of different shading rates on photosynthetic gas exchange parameters of konjac leaves

$P_{\mathrm{n}}$ is an important index to measure photosynthesis, and it is obtained by determining the leaf gas exchange. This index is greatly affected by the plant growth state, light 
720

intensity, and other environmental conditions. In this experiment, moderate shading could improve the $P \mathrm{n}$ of konjac leaves. $G s$ and $\operatorname{Tr}$ under the shading treatments were high. On the one hand, shading changes the absorption and distribution of light by plants. On the other hand, it reduces the inhibition of strong light on photosynthesis, which breaks the midday depression of photosynthesis. At this moment, the shaded plants are in a moderate light level, which is conducive to photosynthesis, stomatal opening, and transpiration. This is consistent with the results of the effects of shading on chlorophyll fluorescence parameters. Under different shading rates, the $C \mathrm{i}$ of the plants showed no significant difference, indicating that $C \mathrm{i}$ is not the main reason for the difference in $P$ n.

\section{Effects of different shading rates on growth indexes and corm weight of konjac plant}

Proper shading can promote plant growth possibly by improving the microenvironment. Improving the environmental temperature, relative humidity, and $\mathrm{CO}_{2}$ concentration can lead to the acceleration of growth. It may also be related to the reduction of direct light damage to plants through reducing strong light. Santosa et al. (2006) reported that leaf size of elephant foot yam and $A$. muelleri increased with the increase in the shading level, resulting in the production of large corms at a low light intensity. Proper shading can increase the yield of konjac. However, higher shading rate does not correspond to greater yield. Under high shading rate (90\%), the plant organs grew vigorously, the plants were tall, and their leaf area was large. However, the yield under $90 \%$ shading rate was lower than that under $70 \%$ shading rate. Weak light not only reduces $P$ n but also affects the yield and the morphogenesis of plants. Light also affects the transport and distribution of photosynthates among plant organs. Under weak light, the proportion of photosynthates exporting from the leaves decreases, and the proportion of distribution to supporting structure increases, which is beneficial for shaded plants to compete for light. It is an adaptive response, resulting in a reduced proportion of photosynthates distribution to organs (Bepete and Lakso, 1998). It may be one of the reasons why the yield of konjac under high shading rate is lower than that under moderate shading rate.

Due to different growth environment conditions and different light intensities, structural and physiological characteristics that are compatible with light environment have been developed throughout plant evolution. Konjac can adapt to weak light because it is native to tropical dense forests (Liu, 2004). The light intensity varies with region and season. Thus, the shading rate suitable for planting konjac is also different. In areas with longer and stronger sunshine and higher temperature, the higher shading rate should be adopted; in areas with shorter and weaker sunshine and lower temperature, the lower shading rate should be adopted.

\section{Conclusions}

Proper shading promotes the growth of plants by improving the environmental conditions, enlarges leaf area, protects photosynthetic organs from strong light stress, and enhances photosynthetic efficiency and photosynthetic capacity, which are conducive to increasing corm weight. This experiment shows that the konjac plants had strong photosynthetic capacity and high yield when the shading rate was 50\%-70\% for the area.

\section{Conflicts of interest}

The authors declare that there are no conflicts of interest related to this article.

\section{Acknowledgements}

This study was supported by the Science and Technology Plan Project of Sichuan (2014ZZ0031).

\section{References}

Baker NR (2008). Chlorophyll fluorescence: a probe of photosynthesis in vivo. Annual Review of Plant Biology 59:89-113.

Bepete M, Lakso AN (1998). Differential effects of shade on early-season fruit and shoot growth rates in 'Empire' apple. HortScience 33(5):823825.

Bjorkman O, Demming B (1987). Photon yield of $\mathrm{O}_{2}$ evolution and chlorophyll fluorescence characteristics at $77 \mathrm{Kamong}$ vascular plants of diverse origins. Planta 170(4):489-504.

Chua M, Baldwin, TC, Hocking TJ, Chan K (2010). Traditional uses and potential health benefits of Amorphophallus konjac K. Koch ex NE Br.Journal of Ethnopharmacology 128(2):268-278.

Dai Y, Shen Z, Liu Y, Wang L, Hannaway D, Lu H (2009). Effects of shade treatments on the photosynthetic capacity, chlorophyll fluorescence, and chlorophyll content of Tetrastigma hemsleyanum Diels et Gilg. Environmental and Experimental Botany 65(2-3):177-182.

Douglas JA, Follett JM, Waller JE (2005). Research on konjac (Amorphophallus konjac) production in New Zealand. Acta Horticulturae 670:173-180.

Evans JR (2013). Improving photosynthesis. Plant Physiology 162(4):17801793.

Fu Z, Xie SQ, Xu WG, Yan S, Chen JW (2016). Characteristics of photosynthesis and chlorophyll a fluorescence in Amorphophallus albus during vigorous growth under different light intensity. Chinese Journal of Applied \& Environmental Biology 22(2):446-454.

Genty B, Briantais JM, Baker NR (1989). The relationship between the quantum yield of photosynthetic electron transport and quenching of chlorophyll fluorescence. Biochimica et Biophysica Acta (BBA)-General Subjects $990(1): 87-92$

Harjoko D, Sakya AT, Widijanto H (2016). The influence of shading intensity and foliar fertilizer concentration on growth and yield of konjac (Amorphophallus oncophylluss). In: The 2nd International Rainforest Conference - Climate Change Mitigation through Sustainable Rainforest Farming and Community-Based Livelihood. Surakarta, Indonesiapp 106-110.

Inaba K (1984). Effect of shading on leaf anatomy in Konjak plant (Amorphophallus konjac K. Koch). Japanese Journal of Crop Science 53(3):243-248. 
Inaba K, Chonan N (1984). The effect of light Intensity on ultrastructure of chloroplasts in Konjak (Amorphophallus konjac K. Koch). Japanese Journal ofCrop Science 53(4):503-509.

Inoue T, Inanaga S, Sugimoto Y, El Siddig K (2004). Contribution of preanthesis assimilates and current photosynthesis to grain yield, and their relationships to drought resistance in wheat cultivars grown under different soil moisture. Photosynthetica 42(1):99-104.

Koblizek M, Kaftan D, Nedbal L (2001). On the relationship between the non-photochemical quenching of the chlorophyll fluorescence and the Photosystem II light harvesting efficiency. A repetitive flash fluorescence induction study. Photosynthesis Research 68(2):141-152.

Li YM, Hu YH, Lv HZ, Zhao YX, ZhangJP (2001). A preliminary study on photosynthetic performance during tuber expansion period of elephant-yam (Amorphophallus rivieri Durieu) grown in the north of China Journal of Agricultural University of Hebei 24(4):14.

Liu PY, Chen JF (1984). Research on photosynthetic capacity of elephantfoot yam. Journal of Southwest Agricultural College 4:21-26.

Liu PY (2004).Konjac. Chinese Agriculture Press, Beijing.

Mauro RP, Occhipinti A, Longo AMG, Mauromicale G (2011). Effects of shading on chlorophyll content, chlorophyll fluorescence and photosynthesis of subterranean clover. Journal of Agronomy and Crop Science 197(1):57-66.

Miura K, Osada A (1981). Effect of shading on photosynthesis, respiration, leaf area and corm weight in konjak plants (Amorphophallus konjak $\mathrm{K}$. Koch).Japanese Journal ofCrop Science 50(4):553-559.

Murchie EH, Lawson T (2013). Chlorophyll fluorescence analysis: a guide to good practice and understanding some new applications. Journal of Experimental Botany 64(13):3983-3998.
Roháček K (2002). Chlorophyll fluorescence parameters: the definitions, photosynthetic meaning, and mutual relationships. Photosynthetica 40(1):13-29.

Santosa E, Sugiyama N, Nakata M, Lee ON (2006). Growth and corm production of Amorphophallus at different shading levels in Indonesia. Japanese Journal of Tropical Agriculture 50(2):87-91.

Schreiber U, Bilger W, Neubauer C (1995). Chlorophyll fluorescence as a nonintrusive indicator for rapid assessment of in vivo photosynthesis. In: Schulze ED, Caldwell MM (Eds). Ecophysiology of photosynthesis. Springer, Berlin, Heidelbergpp 49-70.

Seo GS, Lee JY, Song NH, Sin BW, Lee HD (1988). Effect of shading and mulching materials on the characteristics and yield of elephant food (Amorphophallus komjac). The Research Reports of the Rural Development Administration-Upland and Industrial Crops 30(2):74 78.

van Kooten O, Snel JFH (1990). The use of chlorophyll fluorescence nomenclature in plant stress physiology. Photosynthesis Research 25(3):147-150.

Xu M, Feng X, Hu P (2011). Effects of different shading degrees on konjac soft rot. Hubei Agricultural Sciences 50(23):4856-4857.

Yang AJ, Anjum SA, Wang L, SongJX,Zong XF, LvJ, ... Dong YF (2018). Effect of foliar application of brassinolide on photosynthesis and chlorophyll fluorescence traits of Leymus chinensis under varying levels of shade. Photosynthetica 56(3):873-883.

Zhang Y, Xie B, Gan X (2005). Advance in the applications of konjac glucomannan and its derivatives. Carbohydrate Polymers 60(1):27-31. 